\title{
A study of relevance of Black-Scholes model on option prices of Indian stock market
}

\author{
Amity Business School, \\ Amity University, \\ Expressway, Noida 201301, India \\ Email: anusri2799@gmail.com \\ Email: mshastri@amity.edu \\ *Corresponding author
}

Anubha Srivastava* and Manjula Shastri

\begin{abstract}
In the modern world, with the continuous evolution of the financial market, there has been a continuous development of different financial instruments. Derivative trading is becoming an integral part of stock market .In recent years trading volume in stock market has increased tremendously which has led to the high volatility in the option prices. A derivative is a type of such evolved financial instrument which has attracted the financial marketers all over the world. An option is a financial contract between two or more parties whose value depends on a given underlying asset, and any change in the value of the underlying has a subsequent change in the value of the derivative contract. Black-Scholes option model is used for fair value pricing for option contracts. In this research work, an attempt has been made to find out the relevance of Black-Scholes model values with the market values for stock options. This paper aimed to find out the significant relationship between BSOPM and actual market price. As a conclusion, the study found out that the option values have insignificant relevance to the market values.
\end{abstract}

Keywords: options; Black-Scholes model; fair price; volatility; market value.

Reference to this paper should be made as follows: Srivastava, A. and Shastri, M. (2018) 'A study of relevance of Black-Scholes model on option prices of Indian stock market', Int. J. Governance and Financial Intermediation, Vol. 1, No. 1, pp.82-104.

Biographical notes: Anubha Srivastava has 11 years of vast experience in academics in the area of finance and accounts with strong academic background, i.e., Gold Medal in M.Com, UGC NET and PhD in Finance. Her expert areas are advance accounts, accounting for managers, financial management, CAMA, security and portfolio management, project appraisal and IFRS, etc. She has more than 20 research papers and case studies published in national and international journals. She has imparted training to employees of various organisations such as Delhi Electricity Board, REC, NTPC, IL and FS Gurgaon, TATA Motors, etc.

Manjula Shastri is a doctorate in the area of finance and accounts. Her research work is in the area of financial appraisal. She is presently working at the Amity Business School, Noida part of the Amity University-Uttar Pradesh as an Associate Professor. In her ten years of experience in academics, she has taught financial management, cost and management accounting and management of financial services. As a researcher, she has published several research papers in journals of national and international repute. Apart from teaching, she has delivered training services to reputed organisations like Axis Bank, Tata Motors among others. 
This paper is a revised and expanded version of a paper entitled 'A study of relevance of Black Scholes model on option prices of Indian stock market' presented at The 4th Sebelas Maret International Conference on Business, Economics and Social Science (SMICBESS), Solo, Central Java Indonesia, 9-10 August 2017.

\section{Introduction}

Today, Derivatives trading is worth $\$ 600$ trillion - six times more than the total economic output of the entire world. ${ }^{1}$ The Indian stock market is one of the most attractive places for the investors all over the world, because of the attractive returns on equities and other instruments. The two ${ }^{1}$ main stock exchanges for equity trading in India are the Bombay Stock Exchange (BSE) and the National Stock Exchange (NSE). An option is a type of financial derivative that represents a contract between the seller (option writer) and the buyer (option holder), which offers the buyer the right, not the obligation, to execute the contract. The options contract allows the buyer to buy (or sell) a security or other financial asset at an agreed-upon price (strike price) during a certain period or on a specific date. In 1975, Black emphasised that there are some good reasons for the growing popularity of option trading, such as the fact that the brokerage charge for taking position in options can sometimes be lower than the charge for the equivalent position directly in the underlying stocks.

Derivative contracts exist on a variety of commodities such as corn, pepper, cotton, wheat, silver, etc. besides commodities. Derivatives contracts also exist on a lot of financial underlying assets like stocks, interest rates, exchange rates, etc. In 1976, Cox and Ross introduced several alternative jump and diffusion processes, and provided solutions for the limiting diffusion cases and for the single-stage forms of the jump processes. The explicit solutions have potential empirical applications and a comparative study of them should give additional insight into the structure of security valuation. Derivative products initially emerged as hedging devices against fluctuations in commodity prices. Financial derivatives came into the spotlight in the post-1970 period due to growing instability in the financial markets. However, since their emergence, these products have become popular and by 1990s, they accounted for about two - thirds of total transactions in derivative products. In recent years, the market for financial derivatives has grown tremendously in terms of instruments available, their complexity and also turnover. ${ }^{2}$

In 1973, Black and Scholes developed a theoretical model for the pricing of options, which can deduce the prices of call and put options depending on the relevant factors like the spot value of the underlying, strike price of the option contract, time to maturity, volatility in the prices of the underlying and the risk-free rate of return available in the market. The Black-Scholes mathematical model explains that the price of heavily traded assets follow a geometric Brownian motion with constant drift and volatility (Black and Scholes, 1973). This model of option pricing is based on the fundamental that in the future, the price of the option contract either increases or decreases based on the spot price of the underlying asset. Following are the purpose of the study 
The first purpose of the study is to determine the theoretical prices of options of the stocks; based on the Market capitalisation, using Black-Scholes Option Pricing Model (BSOPM)

The second significant objective is to understand and find out whether there is significant difference between BSOPM prices and the actual market prices.

This study reveals that the volatility play an important role in establishing the relationship between theoretical and actual price, the more is the volatility the higher is the gap between actual and theoretical price. Besides the difference between the model value and actual price can be attributed to many micro and macro factors in financial market. In this research the call option values have been more consistent than put option because of investor sentiment and perception. Another important observation of the study is that the scripts with lower spot prices (underlying price) are more consistent and predictable, because the premiums for such option contracts are also usually low.

\section{Literature review}

This paper tries to find out the relationship between model value and actual value of stocks by testing hypotheses on various parameters. In 1979, Cox et al. concluded that whenever stock price movements conform to a discrete binomial process, or to a limiting form of such a process, options can be priced solely on the basis of arbitrage considerations. Indeed, we could have significantly complicated the simple binomial process while still retaining this property. Though the outcome of the hypothesis test proved that there are overall mismatch and inconsistencies if an investor tries to rely on the model values of the option premiums from the Black-Scholes equation, but if the investor wants to take the advantage of arbitrage opportunity then in this research the daily spreadsheet of the theoretical values of almost all the contracts (at different strike prices of both call and put options) explains that the market values for subsequent days can be predicted with the help of these theoretical values. Hence the arbitrage opportunity exists.

Black and Scholes (1973) presented a theoretical formula to calculate the options prices, which follow a certain systematic pattern based on relevant market factors, which include spot prices, volatility, time to expiry and expected risk-free rate of return.

Sethi and Nilakantan (2016) examines if the Black-Scholes model is a good descriptor of option pricing the research involves an empirical study conducted on ten most active stocks (of NSE) and concluded that involves a significant degree of mispricing. The trading of the option contracts is relatively a recent practice on the exchanges of the Indian stock market, and therefore not much research is done regarding the relevance of the Black-Scholes model on Indian stock market.

Kumar and Agrawal (2017) investigates the efficiency of Black-Scholes model used for valuation of call option contracts written on Eight Indian stocks quoted on NSE. It has been generally observed that the B\&S Model misprices options considerably on several occasions and the volatilities are 'high for options which are highly overpriced. Mispriced worsen with the increased in volatility of the underlying stocks. Panduranga (2013) analysed banking stocks to check the reliability of the Black-Scholes model, and three out of four stocks showed no significant difference, yet there was scope of improvement in the model to account for market conditions. 
Bi et al. (2014) used GARCH and Black-Scholes model to study the option prices of Indian stock market, and found out that the market prices of the options are overpriced as per the model. Nagendran and Venkateswar (2014) carried out different sample tests to find the relevance of the model on the call options in Indian stock market, and they concluded that an increase in the volatility of a stock, results in the increased deviations of the model value and the actual market value.

Kim et al. (1997) tested the impact of implied volatility across option pricing models for at-the-money put options. It was concluded that the implied volatility estimates calculated from the Black-Scholes European option pricing model were approximately similar to those obtained from other more complex pricing models. In 1987, Hull and White developed a solution in a series form for the situation in which the stock price is instanceously uncorrelated with volatility. We do not assume that volatility is a traded asset.

Sharma and Arora (2015), tested the model on a selected group of ten stocks of NSE, and came out with a conclusion that Black-Scholes model is partially relevant, mainly because it is theoretical, and does not account for market perceptions. Frino et al. (1991) carried out cross sectional tests of the model using the historical data. He concluded that the Black-Scholes model cannot be rejected. He carried out a time series analysis of mispricing in order to determine whether that could be attributed to a market learning effect over time.

Ramazan and Aslih (2003) pointed out that the Black-Scholes pricing errors are larger in the deeper out-of-the-money options, and mispricing increases with increased volatility. This result indicated that the Black-Scholes model is not proper pricing tool in high volatility with considerably lower errors for out-of-the-money call and put options.

Angeli and Bonz (2010) evaluated the performance of the Black-Scholes model for price stock index options. They calculated the theoretical values of options under the Black-Scholes assumptions and compared these values with the real market prices in order to put the degree of deviation in two different time windows. They found clear evidence to state that BS model performed different in the period before and after financial crisis.

Bakshi et al. (1997) stated that taking care of the stochastic volatility is the first important step in improving the Black-Scholes formula. To account for the negative skewness and excess kurtosis implicit on option prices, each model with stochastic volatility requires highly implausible levels of volatility return correlation and volatility variation. McKenzie et al. (2007) stated that the Black-Scholes model is relatively accurate. Comparing the qualitative regression models provides evidence that the Black-Scholes model is significant at the $1 \%$ level in estimating the probability of an option being exercised. Chappell (1992) explained that one problem with the Black-Scholes analysis is that the mathematical skills required in the derivation and solution of the model are fairly advanced and probably unfamiliar to many economists.

According to Ramazan and Aslihan (2003), Black-Scholes model is not the proper pricing tool in high volatility situations, especially for very deep out of-the-money options. For the deepest out-of-the-money options, the Black-Scholes prices overestimate market prices whereas market prices are underestimated for the deeper and near out-of-the money options. In particular, the performance of the Black-Scholes model in explaining the observed market prices is quite poor for the deepest out-of-the-money options. According to Khan (2012) changes in Black-Scholes option pricing model 
formula is required by adding some new variables on the basis of given assumption related to risk-free rate of interest, and he also emphasised on the calculation process of new risk-free interest rate on the basis of modified variable. In 2013, Khan et al. conducted research and identified the various situations in empirical testing of modified and original Black-Scholes formula with respect to the market value on the basis of assumed and calculated risk-free interest rate.

Arora and Sharma (2013) calculated the volatility and threw a light on that how the implied volatility levels of an option contract of a stock is connected to the pricing of that option .He also explained about the overpricing and underpricing of the stocks the basic approach was used to determine the volatility of a stock and used this historical volatility in the Black-Scholes model in order to determine the implied volatility and then compared the historical volatility with the implied volatility to find whether an option is fairly priced.

\section{Research methodology}

Research is an academic activity and as such should be used in advance manner and in a technical sense. For this study, the stocks of the companies listed on NSE are divided on the basis of market capitalisation. Seven stocks are selected from each of large-cap, mid-cap and small-cap. The option contracts are taken for the month of January 2017, to be expired on 25/1/2017. Hence samples of 18 trading days (2/1/2017 to 25/1/2017), for both call and put option contracts for 3 different strike prices of each of the 21 stocks are taken. The theoretical option prices of all these stocks are calculated using the Black-Scholes model, which uses following variables; spot price, strike price, volatility, risk-free rate of return an time to maturity. The volatility, which is an important parameter to calculate the prices of the options using Black-Scholes model, has been calculated using the monthly closing prices of the last five years, taken from $\mathrm{http}: / /$ in.finance.yahoo.com. The data of closing prices of shares and the actual option premiums are collected from the website http://www.nseindia.com and http://www.bseindia.com. The model is based on certain assumptions, including:

- the options are European and can only be exercised at expiration

- no dividends payments on stock during the life of the option

- efficient markets (i.e., market movements cannot be predicted)

- no commissions

- there are no risk less arbitrage opportunities.

- the risk-free rate and volatility of the underlying are known and constant

- the prices of the stocks follow a lognormal distribution; that is, returns on the underlying are normally distributed.

The Black-Scholes formula takes the following variables into consideration:

- current underlying price

- options strike price 
- time until expiration, expressed as a percent of a year

- implied volatility

- risk-free interest rates.

Using the Black-Scholes equation, the premium for a call option can be calculated as:

$$
\mathrm{C}=\mathrm{S} * \mathrm{~N}(\mathrm{~d} 1)+\mathrm{K} * \mathrm{e}^{(-\mathrm{r} * \mathrm{t})} * \mathrm{~N}(\mathrm{~d} 2)
$$

where

C call premium

S current stock price (spot price)

$\mathrm{t}$ time until option exercise (in years)

$\mathrm{K}$ strike price of the option contract

$\mathrm{r}$ risk-free interest rate available in the market

$\mathrm{N}$ cumulative standard normal distribution

e exponential term.

and $\mathrm{d} 1$ and $\mathrm{d} 2$ are calculated as follows:

$$
\begin{aligned}
& \mathrm{d} 1=\frac{\ln (\mathrm{S} / \mathrm{K})+\left(\mathrm{r}+\mathrm{v}^{2} / 2\right) * \mathrm{t}}{\mathrm{v} * \mathrm{t}} \\
& \mathrm{d} 2=\mathrm{d} 1-(\mathrm{v} * \mathrm{t}) \text { or } \mathrm{d} 2=\frac{\ln (\mathrm{S} / \mathrm{K})+\left(\mathrm{r}+\mathrm{v}^{2} / 2\right) * \mathrm{t}}{\mathrm{v} * \mathrm{t}}
\end{aligned}
$$

V volatility of the stock (standard deviation)

In natural log

The model is essentially divided into two parts:

The first part

$\mathrm{S} * \mathrm{~N}(\mathrm{~d} 1) \quad$ multiplies the price by the change in the call premium in relation to a change in the underlying price. This part of the formula shows the expected benefit of purchasing the underlying outright.

The second part

$\mathrm{K} * \mathrm{e}(-\mathrm{r} * \mathrm{t}) * \mathrm{~N}(\mathrm{~d} 2) \quad$ provides the current value of paying the exercise price upon expiration.

The value of the option is calculated by taking the difference between the two parts, as shown in the equation.

Similarly, the premium for the put option can be calculated by using the formula:

$$
\mathrm{P}=\mathrm{S} * \mathrm{~N}(-\mathrm{d} 1)+\mathrm{K} * \mathrm{e}^{(-\mathrm{r} * \mathrm{t})} * \mathrm{~N}(-\mathrm{d} 2)
$$


The following steps are applied for the determining the fair option prices and implies volatility of stock options:

Step 1 First, we calculate the historical volatility using the daily log returns by using moving average method.

Daily return $=$ Ln (today's closing price $/$ yesterday's closing price)

Daily standard deviation $(\mathrm{SD})=($ Variance of daily returns $) \wedge 0.5$

Historical volatility $=$ Daily $\mathrm{SD} \times(250) \wedge 0.5$

(Here we consider 250 trading days in a year)

Step 2 We get all required value in the black formula from the NSE website and use them in the Black-Scholes model and we get the fair value of call and put options of various strike prices.

In the next step, we will find the differences between Model value and the actual market values.

Step 3 Now, we can compare the fair option premium with the actual value of option premium.

The historical volatility is calculated using the monthly log returns of the corresponding stocks.

Monthly return $=\operatorname{Ln}$ [(this month's closing price)/(last month's closing price)]

Volatility $=$ standard deviationof the monthly returns

The risk-free rate of return is taken as $6.88 \%$, which is the current yield on ten-year bonds issued by Indian government.

The time to maturity is calculated as the fractional value of the number of days remaining to the maturity date.

The spot prices of the different stocks are taken from the website www.nseindia.com.

Three different strike prices of all the stocks are taken, and then the option prices of the call option and put option contracts are calculated using the Black-Scholes model. The actual (or market) prices of all these contracts are taken from www.nseindia.com.

For finding whether there is a significant difference between model values and actual values, we have used paired sample $t$ test, where

Null hypothesis (H0) There is no significant difference between BS model values and actual market values.

Alternate hypothesis (Ha) There is significant difference between BS model values and actual market values.

At $95 \%$ level of confidence:

If P-value $>0.05$ then null hypothesis is accepted.

A total of 126 hypotheses are formed ( 63 for call option contracts, and 63 for put option contracts). 
These hypotheses are tested using the paired sample $t$ test, which compares the means and standard deviations of the two series of numbers, to evaluate if there is a significant difference between the two series of numbers or not.

This analysis includes only seven stocks from each of large-cap, mid-cap and small-cap for only a period of 18 trading days to calculate model based fair price. Volatility, which is an important parameter to calculate the prices of the options using the Black-Scholes model, too, has been calculated using the monthly closing prices of the last five years only. Hence this study has time and data limitation. Because of limited sampling and time duration, the conclusion drawn may not hold true for the entire population. The constraints of the model should also be considered as limitation of the study.

\section{Data analysis and interpretation}

The fair values have been calculated by using Black-Scholes option pricing model. The Model values and the market values are presented in Tables 1-6. The two set of values are then compared to find out if there is any significant difference in the actual values and market values, with the help of the paired sample $t$ test. Further, Tables 7 and 8 shows the result of the paired sample $t$ test results of 126 sets where each set has the historical price data of 17 days. The paired sample t test is used between the Black-Scholes pricing model value and the actual market prices of option contracts.

From paired sample $t$ test, it was concluded that out of 63 call option sets, the null hypothesis is accepted in five pairs which show that there is no significant difference between fair prices and actual prices for these sets. In remaining 58 call option pairs, the null hypothesis is rejected; it shows that there is significant difference between the fair prices and actual prices.

In case of put option, only one pair out of 63 shows that the difference is insignificant, and other 62 sets show that the difference is significant.

Since, only 6 out of the 126 given sets of the option prices have the p-value greater than 0.05 , it can be concluded that there is a significant difference between the market prices of the option premiums and the values given by the Black-Scholes equation of option pricing.

Though the results of the t-test have presented that there are overall inconsistencies if one tries to depend on the theoretical values of the option premiums from the Black-Scholes equation, but the daily spreadsheet of the theoretical values of almost all the contracts (at different strike prices of both call and put options) shows that the market values for subsequent days can be predicted with the help of these theoretical values, and hence there are arbitrage opportunities.

Moreover, it can be seen that in cases of stocks with high volatility ( $v>15 \%)$, the difference between the predicted and actual values is more as compared to those which are less volatile.

An important observation from the research is that the stocks with lower spot prices (underlying price) are more consistent and predictable, because the premiums for these option contracts are also usually low and do not show much variations, due to the rumours and sentiments of the market. 
Table 1 Call options for large cap stocks

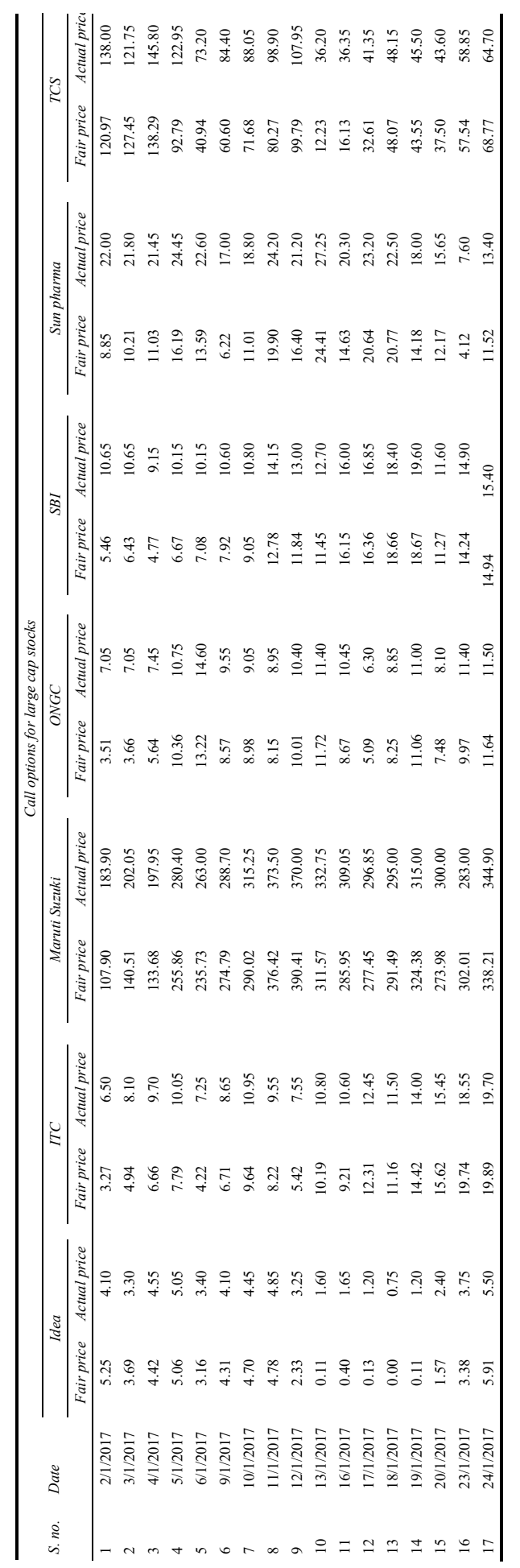


Table 2 Put options for large cap stocks

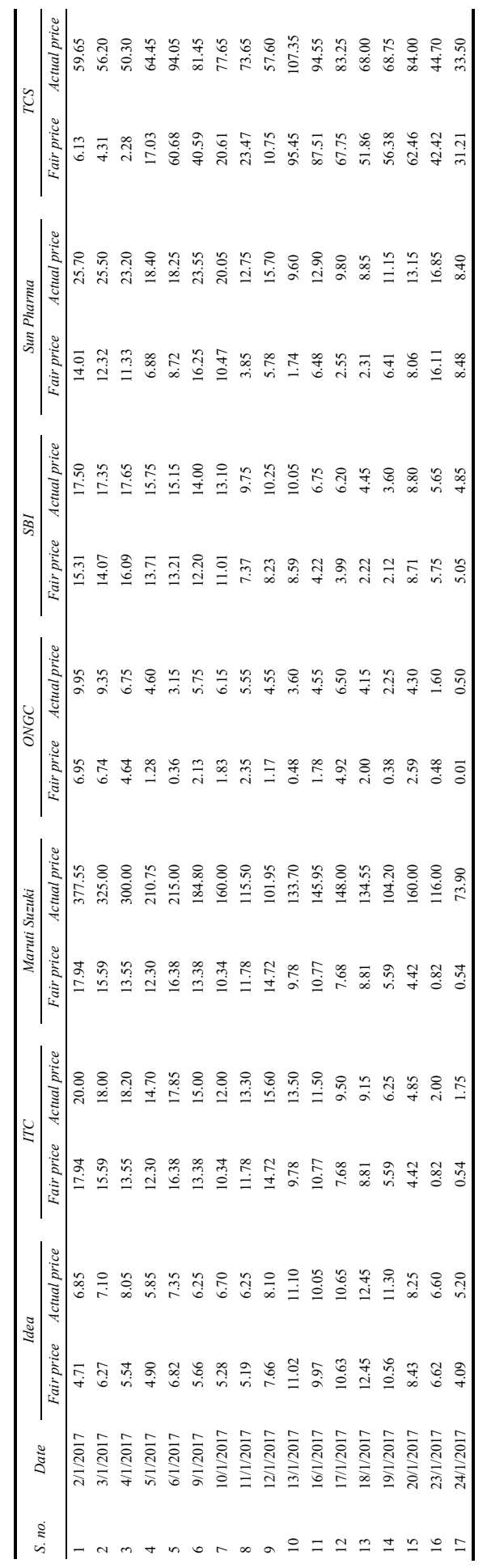


Table 3 Call options for mid cap stocks

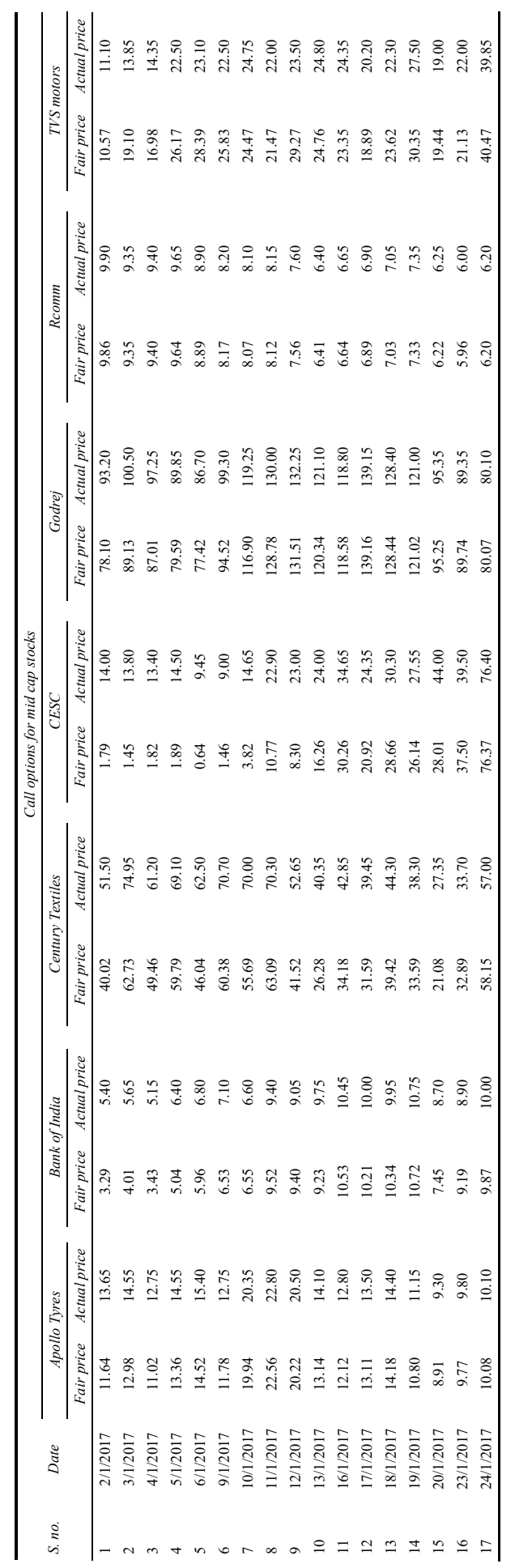


Table 4 Put options for mid cap stocks

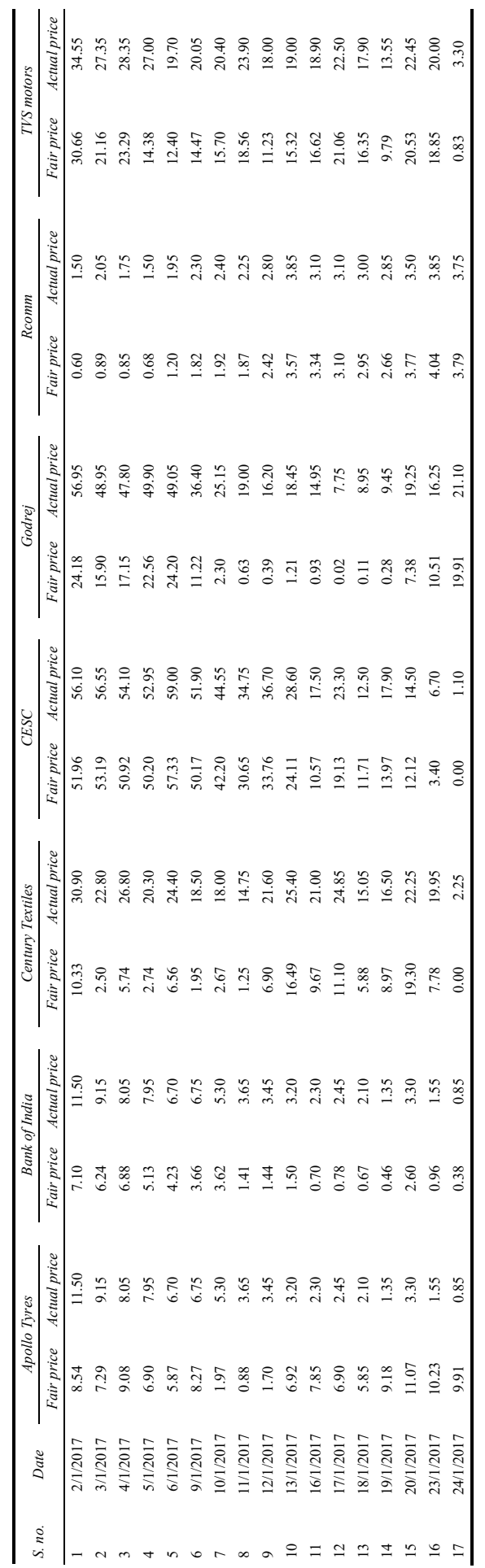


Table 5 Call options for small cap stocks

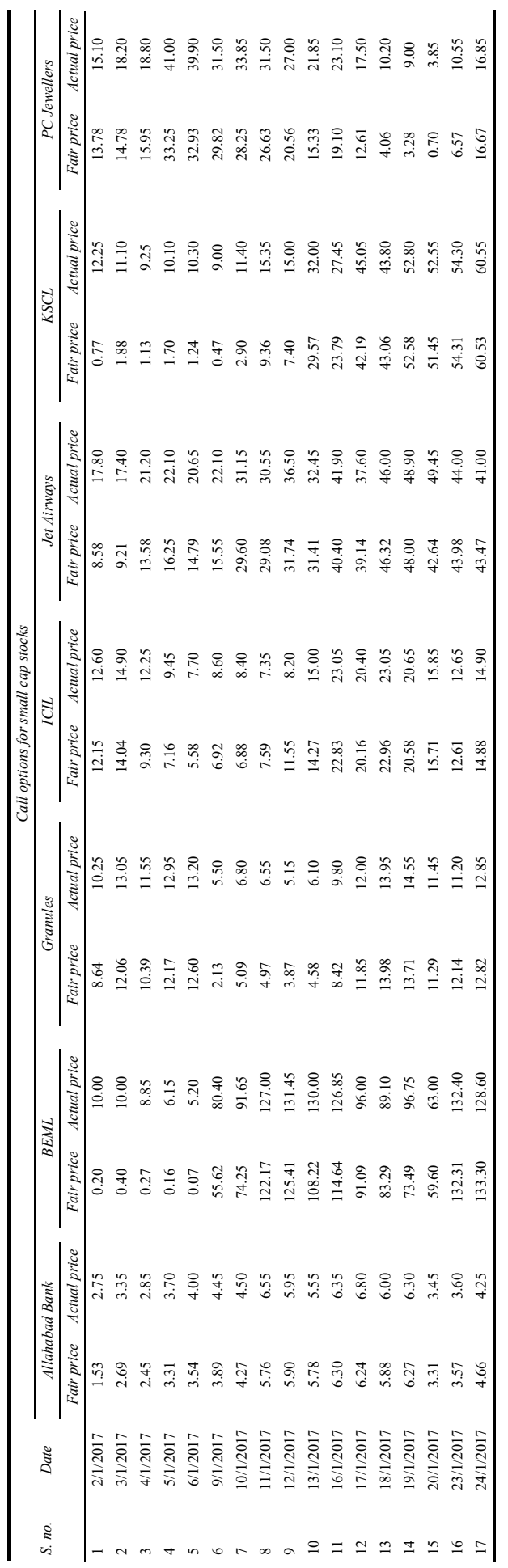


Table 6 Put options for small cap stocks

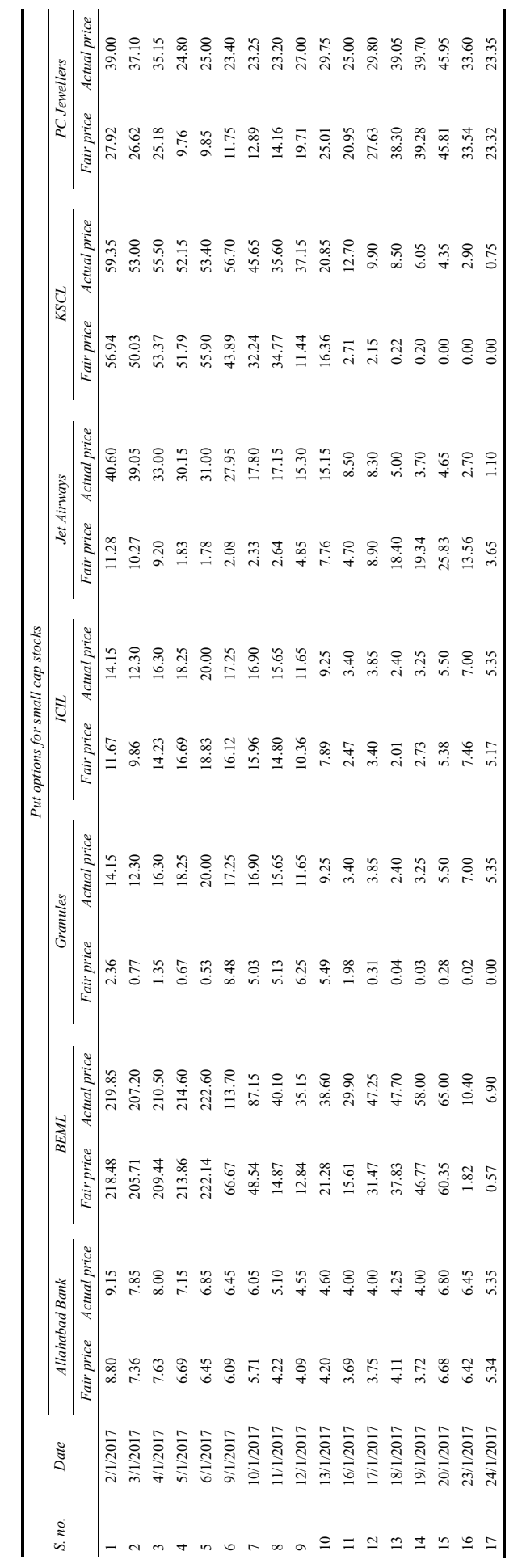


Table 7 Paired sample T-test for Black-Scholes model premium value and actual market premium value call option

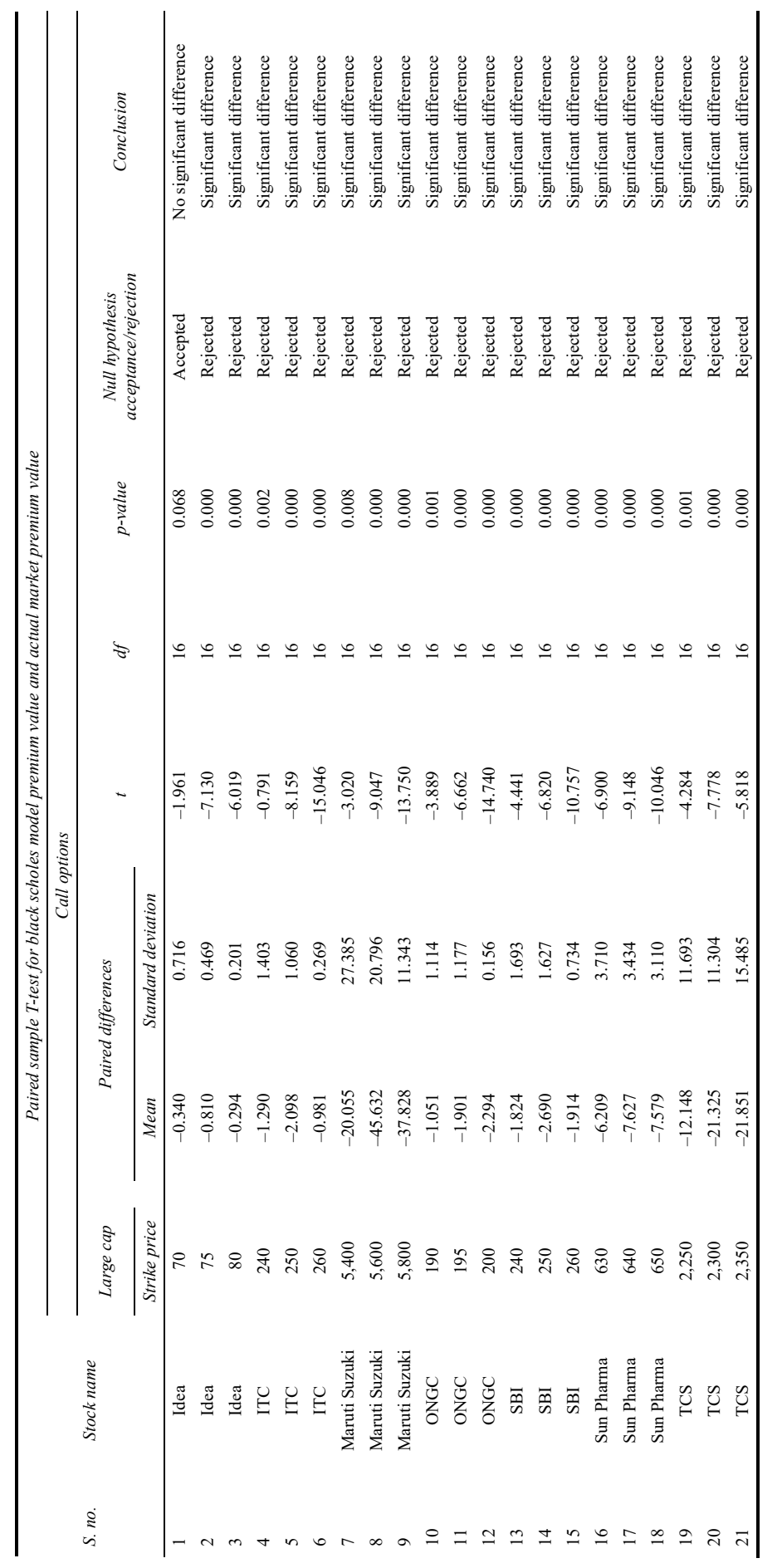


Table 7 Paired sample T-test for Black-Scholes model premium value and actual market premium value call option (continued)

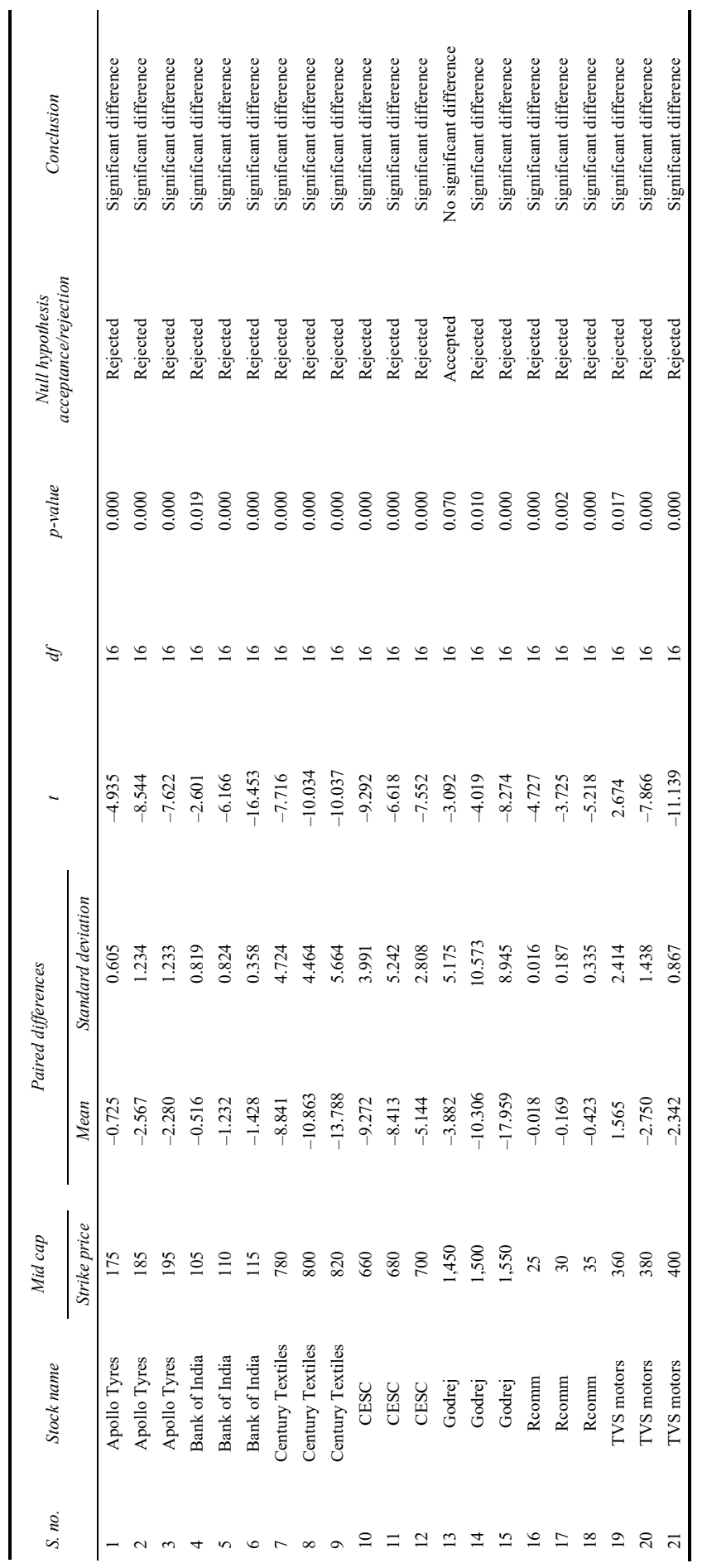


Table 7 Paired sample T-test for Black-Scholes model premium value and actual market premium value call option (continued)

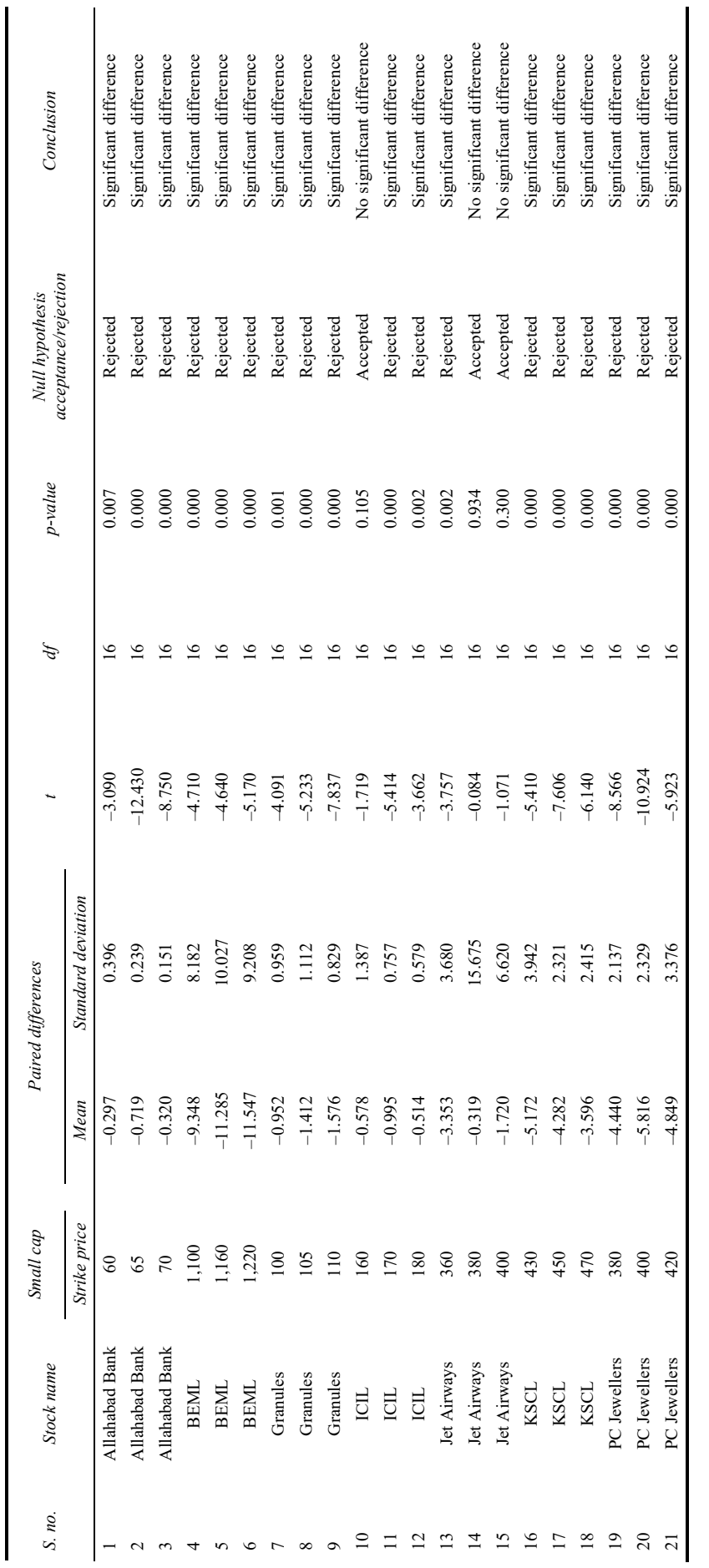


Table 8 Put options

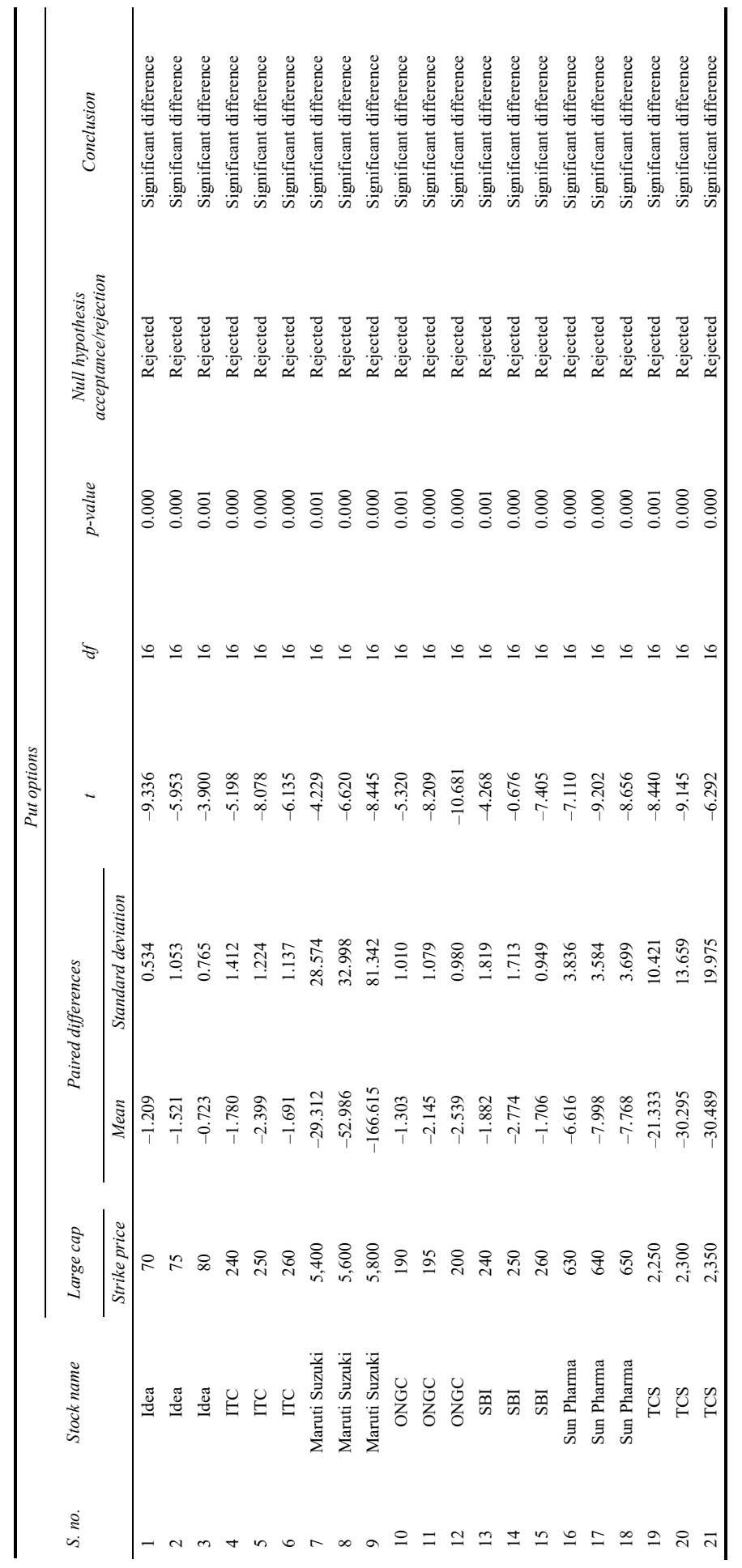


Table 8 Put options (continued)

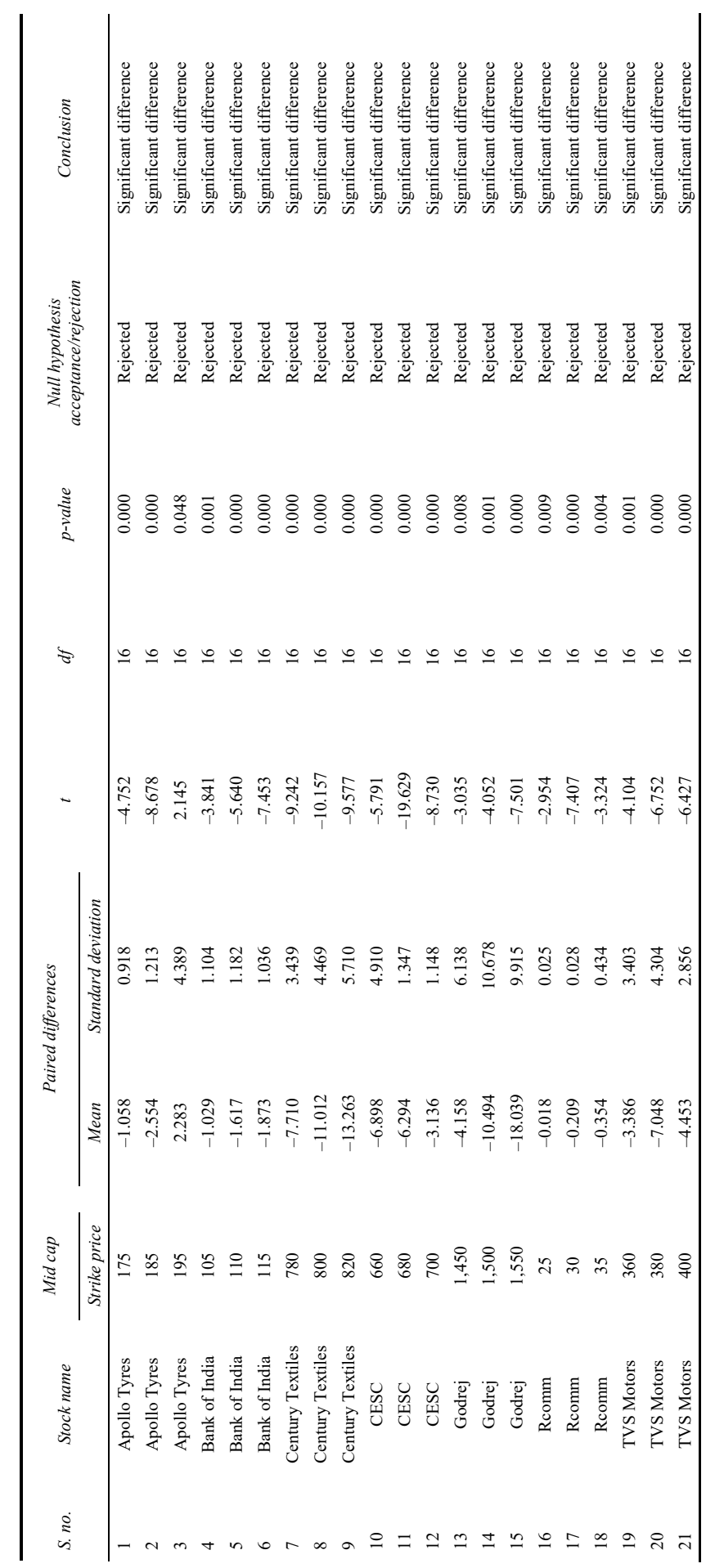


Table 8 Put options (continued)

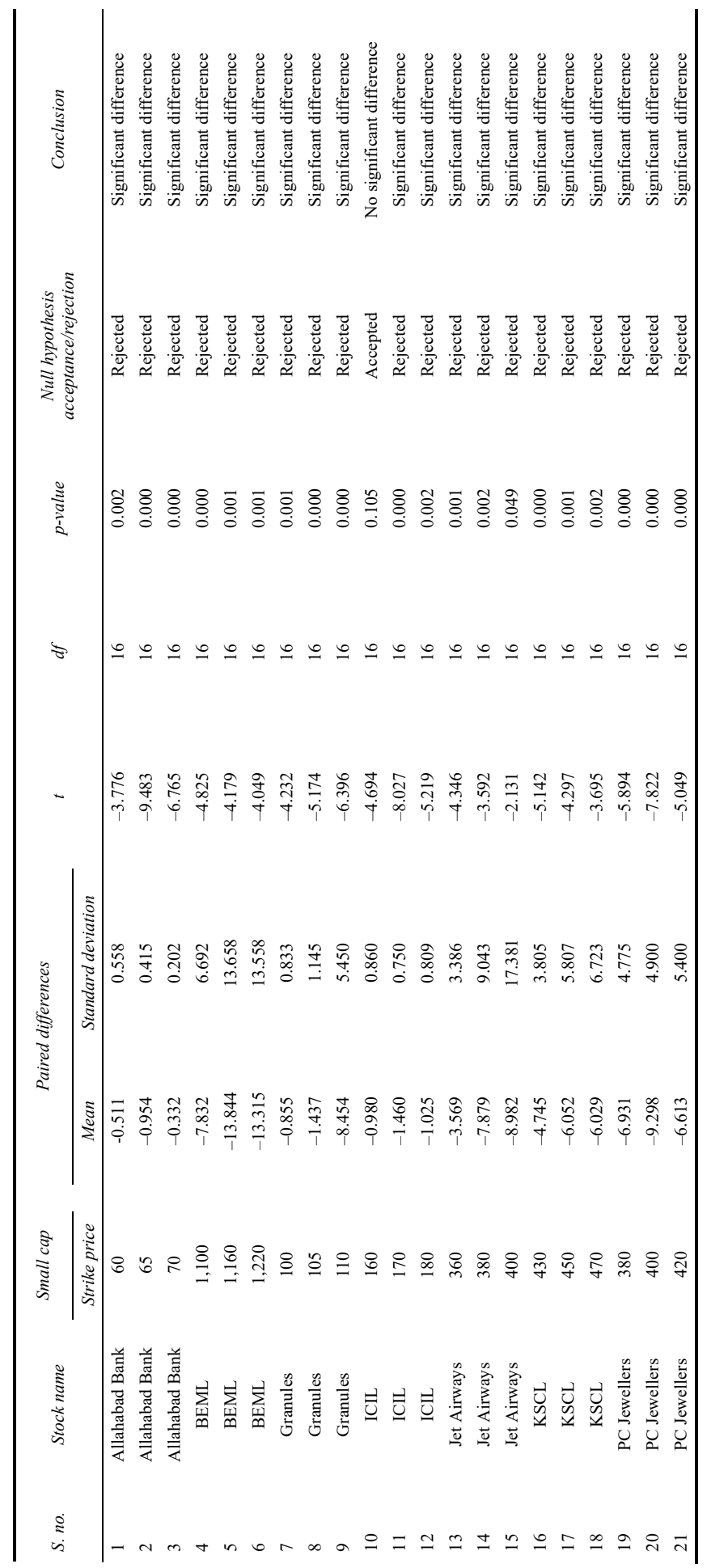




\section{Conclusions}

A conclusion can be derived is that, the difference in the predicted and actual prices increases as the moneyness of an option contract moves from the in-the-money to out-of-the-money, which can be reasoned as when the stocks start behaving against the expectations of the investors, there is an increase in the volume of the trade which leads to an increase in volatility, and hence an increased difference between the predicted values and actual values. The Black-Scholes model is partially relevant and it can be made effective by taking into consideration all other constraints of the model to make the option pricing more effective. In spite of several loopholes in Black-Scholes option pricing model, there are several reasons for wide use of this model. The most important one is that the concepts behind the Black-Scholes analysis provide the framework for thinking about option pricing.

The significant differences in a large number of hypotheses sets can be attributed a number of different factors that drive the financial market. The prices of the options, just like any other commodity, are dependent on its demand and supply in the market.

The prices of the options are also dependent on the news related to the market, or any particular industry, or any particular company. These news and information affect the market sentiments of the related stocks, and therefore drives the prices accordingly.

The market prices of the options depend on the prevailing market conditions, such as a forecasted slump in the economy, a decline in the company's performance, expansion opportunities of a company, etc.

The prices of call option are more consistent with the theoretical values, than those of the put option. This may be because of the perceptions of the investors during the specified period of research, who may be bidding for the Bullish market, and hence the prices of the out-of-the-money contracts for the put options are significantly different.

Because the market remains in the semi-strong form, all the investors have the same information available to them. They look for the underpriced securities and when the demand of the underpriced securities increase, their price also starts increasing to the fair value.

Most of the limitations of the Black-Scholes model are fundamental and, thus, it is crucial to come up with models that will take into consideration some of the assumptions not considered under the Black-Scholes models. And, there have been a number of other models which have been developed in recent times which try to emulate the exact characteristics of the market, but the fundamental behind these models is the Black-Scholes model.

\section{References}

Angeli, A. and Bonz, C. (2010) Changes in the Creditability of the Black-Scholes Option Pricing Model Due to Financial Turbulences, Master's thesis, Umeå School of Business and Economics.

Arora, K. and Sharma, M. (2013) 'Analysis of option pricing using implied volatility of equity option contracts', Emerging Trends in Business and Economy, Excel Books, pp.13-28.

Bakshi, G., Cao, C. and Chen, Z. (1997) 'Empirical performance of alternative option pricing models', Journal of Finance, LII, December, Vol. 52, No. 5, pp.2003-2049.

Bi, Z., Yousuf, A. and Dash, M. (2014) 'A study on option pricing using GARCH and Black-Scholes-Merton model', Asian Journal of finance \& Accounting, Vol. 6, No. 1, p.425. 
Black, F. (1975) 'Facts and fantasy in the use of options', Financial Analysts Journal, Vol. 31, No. 4, pp.36-41.

Black, F. and Scholes, M. (1972) 'The valuation of option contracts and a test of market efficiency', Journal of Finance, May, Vol. 27, No. 2, pp.399-418.

Black, F. and Scholes, M. (1973) 'The pricing of options and corporate liabilities', Journal of Political Economy, Vol. 81, No. 3, pp.637-659.

Cox, J. and Ross, S. (1976) 'The valuation of options for alternative stochastic processes', Journal of Financial Economics, Vol. 3, pp.145-166.

Cox, J., Ross, S. and Rubinstein, M. (1979) 'Option pricing: a simplified approach', Journal of Financial Economics, Vol. 7, pp.229-263.

Frino, A., Khan, E. and Lodh, S.C. (1991) The Black Scholes Call Option Pricing Model and the Australian Options Market: Where Are We After 15 Years, Faculty of Commerce-Accounting \& Finance, Working Papers, p.125.

Hull, J. and White, A. (1987) 'The pricing of options on assets with stochastic volatilities', Journal of Finance, Vol. 42, pp.281-300.

Khan, M., Gupta, A. and Siraj, S. (2013) 'Empirical testing of modified Black-Scholes option pricing model formula on NSE derivative market in India', International Journal of Economics and Financial Issues, Vol. 3, No. 1, pp.87-98.

Khan, M.U., Gupta, A. and Siraj, S. (2012) 'Empirical testing of modified Black-Scholes option pricing model formula on NSE derivative market in India', International Journal of Economics and Financial Issues, Vol. 3, No. 1, pp.87-98.

Kim, H., Rhim, J.C. and Khayum, M.F. (1997) 'An empirical investigation of put option pricing: a specification test of at-the-money option implied volatility', Journal of Financial and Strategic Decisions, Vol. 10, No. 1, p.2.

Kumar, R. and Agrawal, R. (2017) 'An empirical investigation of the Black-Scholes call option pricing model with reference to NSE', International Journal of BRIC Business Research (IJBBR), May, Vol. 6, No. 2, pp.1-11.

McKenzie, S., Gerace, D. and Subedar, Z. (2007) 'An empirical investigation of the Black-Scholes model: evidence from the Australian Stock Exchange', Australasian Accounting, Business and Finance Journal, Vol. 1, No. 4, p.72.

Nagendran, R. and Venkateswar, S. (2014) 'Validating Black-Scholes model in pricing Indian stock call options', Journal of Applied Finance \& Banking, Vol. 4, No. 3, p.5.

Panduranga, V. (2013) 'Relevance of Black-Scholes option pricing model in indian derivatives markets - a study of cement stock options', International Journal of Multidisciplinary Research in Social and Management Sciences, Vol. 1, No. 4, pp.91-95.

Ramazan, G. and Aslihan, S. (2003) 'Degree of mispricing with the Black-Scholes model and nonparametric cures', Annals of Economics and Finance, Vol. 4, No. 1, pp.73-101.

Ramazan, G. and Aslihan, S. (2003) 'Degree of mispricing with the Black-Scholes model and nonparametric cures', Annals of Economics and Finance, Vol. 4, No. 1, pp.73-101.

Sethi, A. and Nilakantan, N. (2016) 'Applicability of Black-Scholes model in Indian capital markets', JBIMS Research Conference, Somaiya Institute of Management Studies and Research.

Sharma, M. and Arora, K. (2015) 'Study of relevance of Black-Scholes model in Indian stock option market', International Journal Of Advance Research And Innovative Ideas In Education, Vol. 1, No. 4, p.324. 


\section{Notes}

1 E book on the use of financial derivatives in risk management purposes of non-financial firms in Bosnia and Herzegovina by Adnan rovčanin aide hanić p.66.

2 An introduction to derivative market by shodhganga, international conference paper, p.1.

\section{Appendix}

List of stocks chosen for study

\begin{tabular}{lclllc}
\hline Large-cap & & \multicolumn{3}{c}{ Mid-cap } & Small-cap \\
\hline 1 & Idea & 1 & Apollo Tyres & 1 & Allahabad Bank \\
2 & ITC & 2 & Bank of India & 2 & BEML \\
3 & Maruti Suzuki & 3 & Century Textiles & 3 & Granules \\
4 & ONGC & 4 & CESC & 4 & ICIL \\
5 & SBI & 5 & Godrej & 5 & Jet airways \\
6 & Sun Pharma & 6 & RComm & 6 & KSCL \\
7 & TCS & 7 & TVS Motors & 7 & PC Jewellers \\
\hline
\end{tabular}

